\title{
Small Signal Stability Analysis for a DFIG-Based Offshore Wind Farms Collected Through VSC-HVDC Transmission System
}

\author{
Kai Liao, Zhengyou He, Bin Sun, Yong Jia \\ School of Electrical Engineering, Southwest Jiaotong University, Chengdu, China \\ Email: liaokai_lk@foxmail.com
}

Received April, 2013

\begin{abstract}
This paper modeled a doubly fed induction generator (DFIG) - based offshore wind farm integrated through a voltage source converter -based high voltage direct current (VSC-HVDC) transmission system, which is collected with infinite bus for small signal stability analysis. The control system of HVDC system is considered for the stability analysis. The impact of the VSC control parameters on the network stability is studied. The lineared dynamic model is employed to do small signal stability analysis by the eigenvalue analysis. The locus of the eigenvalue, which is corresponding to the oscillation model is studied. Time domain simulations conducted in Matlab/Simulink are used to validate the small signal stability analysis.
\end{abstract}

Keywords: DFIG; Offshore Wind Farm; VSC-HVDC; Small Signal Stability

\section{Introduction}

Because the advantages in speed control, reduced flicker, and four-quadrant active and reactive power capabilities, are primarily achieved via control of a rotor side converter. Many large offshore wind farms based on DFIG (Doubly fed induction generator) have been planned around the world wide [1, 2]. The High-voltage dc (HVDC) transmission is emerging as the prospective technology to address the challenges associated with the integration of future offshore wind power [3].

In [4] and [5], a VSC transmission system was used to connect a 6-MWwind farm to the grid. VSC transmission systems were also proposed in [6], for transmitting offshore wind power equipped fixed speed generators to the grid. However, many large wind farms under development will employ DFIG-based wind turbines whose operation and response to net-work disturbances are significantly different from other types of generators. In [7], line commutated HVDC systems were used to connect a large DFIG-based offshore wind farm into the grid. In [li xue] described the use of VSC-HVDC transmission system technology for connecting large DFIG-based wind farms over long distance. New control strategies for normal and grid fault conditions are proposed. To obtain smooth operation, the wind farm side VSC is controlled as an infinite voltage source that automatically absorbs power generated by the wind farm and maintains a stable local ac network.

The dynamic behavior of the doubly fed induction generator (DFIG) has been investigated in many papers. The majority of these studies are based on time-domain simulations to show the impact on power system dynamics $[8,9]$, the performance of decoupled control and maximum power tracking, the response to grid disturbances, the control methods to make the DFIG behave like a synchronous generator [10-13], etc. Time-domain studies offer a direct appreciation of the dynamic behavior in terms of visual clarity. However, the time domain simulation can't observe all oscillation modals [14].

In [15], a model suitable for small-signal stability analysis and control design of multi-terminal dc networks is presented. A generic test network that combines conventional synchronous and offshore wind generation connected to shore via a dc network is used to illustrate the design of enhanced voltage source converter (VSC) controllers. The impact of VSC control parameters on network stability is discussed and the overall network dynamic performance assessed in the event of small and large perturbations.

In this paper, the grid-connected DFIG via VSC-HVDC system is studied. The single-machine infinite-bus (SMIB) approach is followed. The paper is organized as follows. In Section II, the mathematical model is observed. In Section III, modal analysis method and the eigenvalue locus under different controller parameters is 
studied. Section IV presents the conclusion.

\section{Modeling of Study System}

The study system is shown in Figure 1 where a DFIGbased wind farm (100MW form aggregation of 2 MW units) is connected to a VSC-HVDC link.

\subsection{DFIG Generator}

The one-phase equivalent electric circuit of the DFIG is shown in Figure 2. The dynamic equations of DFIG are usually described by transforming the machine ' $a b c$ ' voltage equations into a synchronously rotating frame, referred to as the ' $d-q$ ' frame.

For stability analysis, the generators are modeled as an equivalent voltage source based on transient impedance. The DFIG is modeled as

$$
\begin{aligned}
\frac{d i_{q s}}{d t}= & -\frac{w_{e l} R_{1}}{w_{s} L_{s}} i_{q s}+w_{e l} i_{d s}+\frac{w_{e l} w_{r}}{w_{s}^{2} L_{s}} e_{q s}^{\prime}-\frac{w_{e l}}{T_{r} w_{s}^{2} L_{s}} e_{d s}^{\prime} \\
& -\frac{w_{e l}}{w_{s} L_{s}} v_{q s}+\frac{K_{m r r} w_{e l}}{w_{s} L_{s}} v_{q r} \\
\frac{d i_{d s}}{d t}= & -w_{e l} i_{q s}-\frac{w_{e l} R_{1}}{w_{s} L_{s}} i_{d s}+\frac{w_{e l} w_{r}}{w_{s}^{2} L_{s}} e_{d s}^{\prime}-\frac{w_{e l}}{T_{r} w_{s}^{2} L_{s}} e_{q s}^{\prime} \\
& -\frac{w_{e l}}{w_{s} L_{s}} v_{d s}+\frac{K_{m r r} w_{e l}}{w_{s} L_{s}} v_{d r} \\
\frac{d e_{q s}^{\prime}}{d t}= & w_{e l} R_{2} i_{d s}-\frac{w_{e l}}{T_{r} w_{s}} e_{q s}^{\prime}+w_{e l}\left(\frac{w_{s}-w_{r}}{w_{s}}\right) e_{d s}^{\prime} \\
& -K_{m r r} w_{e l} v_{d r} \\
\frac{d e_{d s}^{\prime}=}{d t} & \left.-w_{e l} R_{2} i_{d s}-\frac{w_{e l}}{T_{r} w_{s}} e_{d s}^{\prime}+w_{e l} \frac{w_{r}-w_{s}}{w_{s}}\right) e_{q s}^{\prime} \\
& +K_{m r r} w_{e l} v_{q r}
\end{aligned}
$$

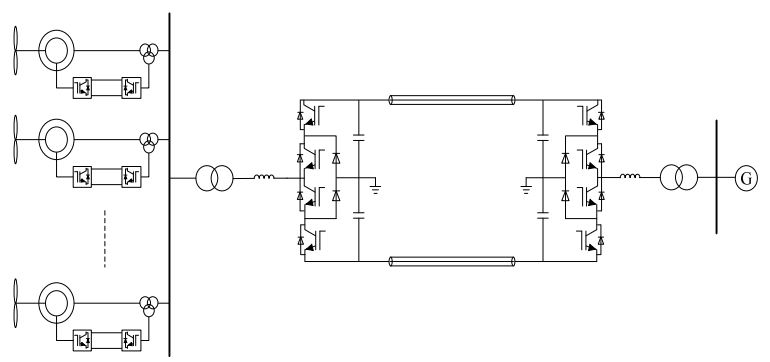

Figure 1. The studied system structure.

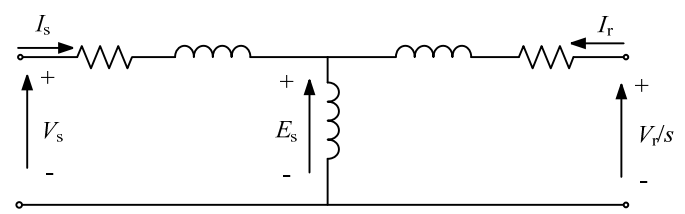

Figure 2. The equivalent electric circuit of the DFIG. where $e_{d s}^{\prime}$ and $e_{d s}^{\prime}$ are the equivalent internal $q$ - and $d$-axis voltages, respectively; $i_{\mathrm{ds}}$ and $i_{\mathrm{qs}}$ are the stator $q$ and $d$ - axis currents, respectively. All the parameters are converted to p.u.

\subsection{Converter}

Figure 3 illustrated a converter circuit diagram in ' $a b c$ ' frame.

The dynamic model of the converter in ' $a b c$ ' frame can be modeled as

$$
\left[\begin{array}{l}
u_{c a} \\
u_{c b} \\
u_{c c}
\end{array}\right]=L \frac{d}{d t}\left[\begin{array}{l}
i_{a} \\
i_{b} \\
i_{c}
\end{array}\right]+R\left[\begin{array}{l}
i_{a} \\
i_{b} \\
i_{c}
\end{array}\right]+\left[\begin{array}{l}
u_{s a} \\
u_{s b} \\
u_{s c}
\end{array}\right]
$$

Use the Park transform as shown in (6), the dynamic model in ' $d$ - $q$ ' frame is shown in (7).

$$
\begin{aligned}
& P=\frac{2}{3}\left[\begin{array}{lll}
\sin w t & \sin \left(w t-120^{\circ}\right) & \sin \left(w t+120^{\circ}\right) \\
\cos w t & \cos \left(w t-120^{\circ}\right) & \cos \left(w t+120^{\circ}\right)
\end{array}\right] \\
& \frac{d}{d t}\left[\begin{array}{l}
i_{m d} \\
i_{m q}
\end{array}\right]=\frac{1}{L}\left[\begin{array}{l}
v_{c d} \\
v_{c q}
\end{array}\right]-\frac{R}{L}\left[\begin{array}{l}
i_{m d} \\
i_{m q}
\end{array}\right]-\frac{1}{L}\left[\begin{array}{l}
u_{s d} \\
u_{s q}
\end{array}\right] \\
& -\left[\begin{array}{cc}
0 & -\omega \\
\omega & 0
\end{array}\right]\left[\begin{array}{l}
i_{m d} \\
i_{m q}
\end{array}\right]
\end{aligned}
$$

where, $V_{\mathrm{c}}$ is the converter voltage and $V_{\mathrm{s}}$ is the grid voltage. Under PWM control, the amplitude of the converter output fundamental voltage is controlled by the modulation index as

$$
V_{c}=M \cdot V_{d c} / 2
$$

In ideal condition, the dc side transmission system can be expressed as

$$
\frac{d V_{d c}}{d t}=\frac{1}{C} \cdot I_{d c}-\frac{3}{4 C}\left(M_{d} \cdot i_{m d}+M q \cdot i_{m q}\right)
$$

where, the $i_{\mathrm{md}}$ and $i_{\mathrm{mq}}$ are the $d$-and $q$ - axis converter current, respectively. $M$ is the modulation index. $V_{\mathrm{dc}}$ is the DC voltage and $I_{\mathrm{dc}}$ is the DC current.

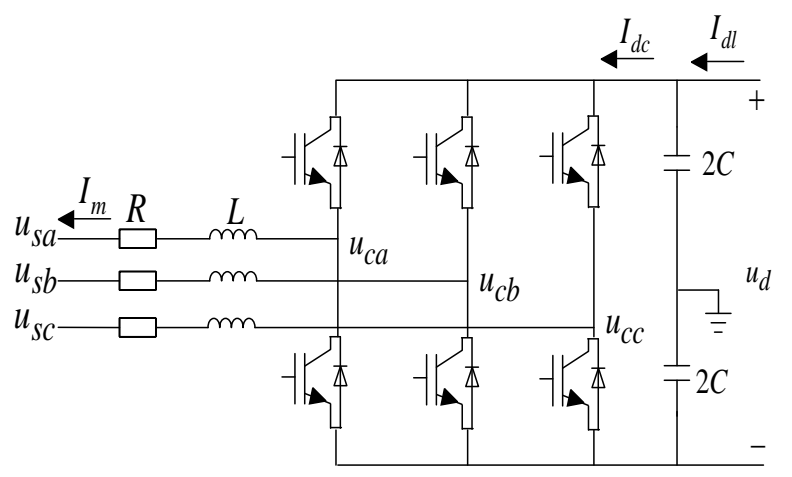

Figure 3. Converter circuit diagram. 


\subsection{Controller of Wind Farm Side Converter}

The aim of the wind farm side converter controller system is to maintain the wind farm network work at constant frequency and voltage. One of the primary requirements for the WFVSC is to collect energy from the wind farm. The output power of DFIG's is controlled by power electronic converters and MPPT system. The network frequency variations have little influence on the power generation. Therefore, to simplify the control system design, the control strategy adopted here is to control the wind farm side converter to resemble an infinite voltage source with constant frequency, voltage amplitude, and phase angle. The control block diagram for the wind farm side converter is shown as Thus, as in the case when a wind farm is connected to an infinite ac system, the power generated by the wind farm is automatically absorbed by the source resembled by the wind farm side converters and then transmitted to the grid via the DC lines. The main tasks for the WFVSC are then to collect energy from the wind farm and to control the ac voltage and frequency of the local wind farm network.

\subsection{Controller of Grid Side Converter}

The wind farm side converter collects energy from wind farm and then transmit it to the power grid via the dc transmission and grid side converter. For the normal operation of a VSC transmission system, its dc link voltage must be maintained at a constant value under all conditions. A constant dc voltage indicates balanced active power flow between the two sides. Abnormal dc link voltage can cause the system to trip and disrupt its normal operation. Furthermore, to achieve this balance, the grid side converter is assigned to control the dc voltage, to ensure the energy collected by the wind farm side converter is transmitted to the grid network. The control system of the grid side converter is shown as Figure 5.

The current control loop is designed as:

$$
u_{d}=\frac{d i_{s d}}{d t}=k_{p 1}\left(i_{s d}^{*}-i_{s d}\right)+k_{i 1} \int\left(i_{s d}^{*}-i_{s d}\right) d t
$$

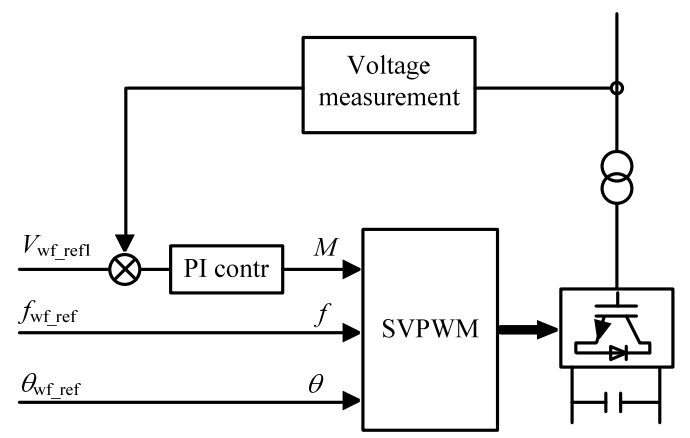

Figure 4. Control block diagram of the wind farm side converter.

$$
u_{q}=\frac{d i_{s q}}{d t}=k_{p 1}\left(i_{s q}^{*}-i_{s q}\right)+k_{i 1} \int\left(i_{s q}^{*}-i_{s q}\right) d t
$$

$i_{s d}^{*}$ is designed as the dc voltage control loop and $i_{s q}^{*}$ is designed as the connection bus voltage control loop.

$$
\begin{aligned}
& i_{s d}^{*}=k_{p 3}\left(V_{d c}^{*}-V_{d c}\right)+k_{i 3} \int\left(V_{d c}^{*}-V_{d c}\right) d t \\
& i_{s q}^{*}=k_{p 2}\left(V_{G}^{*}-V_{G}\right)+k_{i 2} \int\left(V_{G}^{*}-V_{G}\right) d t
\end{aligned}
$$

According to (9), the modulation index $\mathrm{M}$ in dq frame are given as (14) and (15).

$$
\begin{aligned}
& M_{d}=\frac{2 L}{V_{d c}}\left(u_{d}+\frac{R}{L} i_{s d}-\omega_{s} i_{s q}+\frac{1}{L} v_{s d}\right) \\
& M_{q}=\frac{2 L}{V_{d c}}\left(u_{q}+\frac{R}{L} i_{s q}+\omega_{s} i_{s d}+\frac{1}{L} v_{s q}\right)
\end{aligned}
$$

\subsection{DFIG Control}

The DFIG control is comprised by two PWM modulation inverters connected back to back via a dc link. The control system is to ensure the stator frequency of DFIG operates at a constant value, and constraint for maximum power capture. So, the rotor side converter operates as a controlled voltage source since it injects an ac voltage with varying frequency to the rotor to keep the stator voltage frequency be a constant value under varying wind speed. The ac voltage of the rotor-side converter depends on the control objectives. For grid-connected

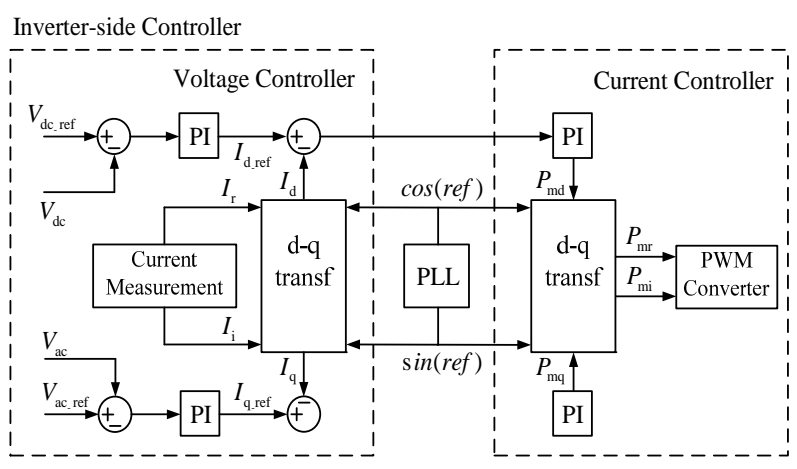

Figure 5. Control block diagram of the grid side converter.

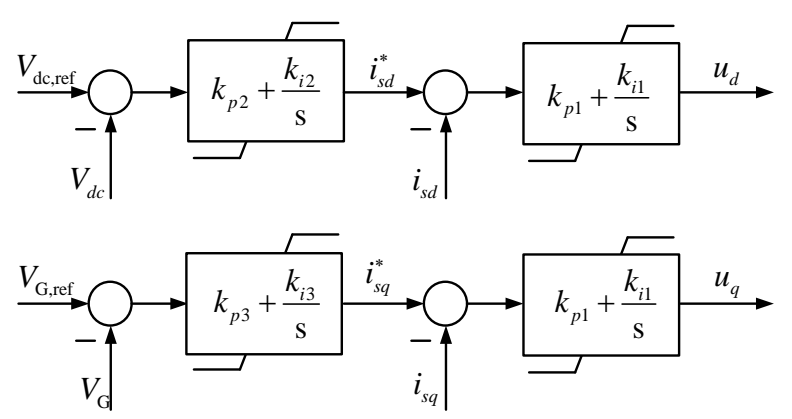

Figure 6. The control system of the grid side converter. 
WECS applications, a sensible choice is to impose a constraint for maximum power capture (equivalent to air gap power, electromagnetic torque, or speed constraint) and another for the voltage control (reactive power constraint). These two objectives determine the DFIG rotor voltage.

For the grid-side converter, the control has to be coordinated so that the dc-link voltage is constant and the desired sharing of reactive power with stator is achieved. Usually, for minimum the converter rating, the reactive power delivered to the grid only from the stator. So, the there is no reactive power delivered to the grid and the rotor side converter works at unity power factor.

In this paper the dynamic of the DFIG rotor is ignored. The rotor side voltage, electromagnetic torque, rotor side current and reactive and active power is constant.

\section{Modal Analysis}

The most direct way to assess small-signal stability is via eigenvalue analysis of a model of the power system. In this case, the "small-signal" disturbances are considered sufficiently small to permit the equations representing the system to be linearized and expressed in state-space form. The model of a power system can be expressed as a set of DAE. The linearized model of the test system can be expressed in state-space form as

$$
\dot{\mathbf{x}}=\mathrm{A} \mathbf{x}+\mathbf{B u}
$$

where $\mathbf{x}$ is the where is the state vector, $\mathbf{u}$ is the input vector, $\mathbf{A}$ is the state matrix, and $\mathbf{B}$ is the input or control matrix. The eigenvalue of the state matrix provide the necessary information about the small-signal stability of the system.

The purpose of this study is to observe the influence of VSC-HVDC control parameters on the small signal stability of the studied system. Vary the value of Kp1, which is employed in the DC line voltage control in VSC-HVDC system. The corresponding eigenvalue displacements are shown in Figure 7. With a larger Kp, the observations indicate that better damped for the oscillation modal.

Varying the control parameters of Ki, which can also employed to DC voltage regulations. The corresponding eigenvalue displacements are shown in Figure 8. The analysis result indicates that the small $\mathrm{Ki}$ are better damped and their oscillation frequencies are lover compared to with large Ki controller.

The time domain simulation result is shown in Figure 9. Under a single phase fault in ac transmission line, the transmission power of the bus, which collected the VSC -HVDC system and wind farm operate at different control parameters is shown in the figure. The result of the time domain simulation validates the results obtained from the small-signal stability analysis above.

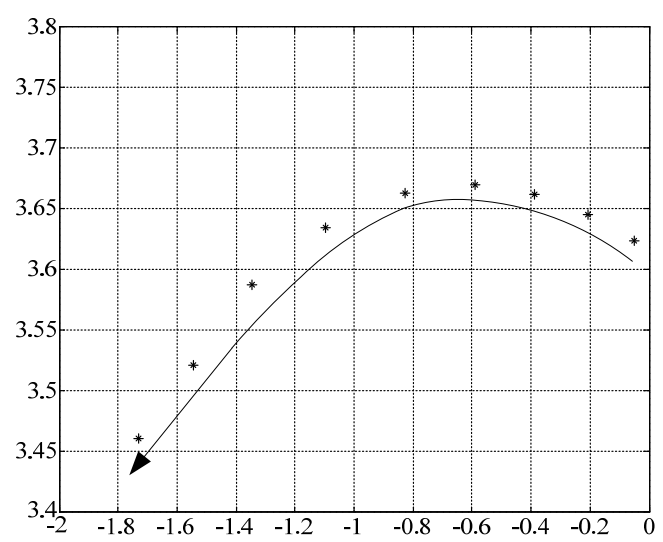

Figure 7. The eigenvalue locus under varying Kp.

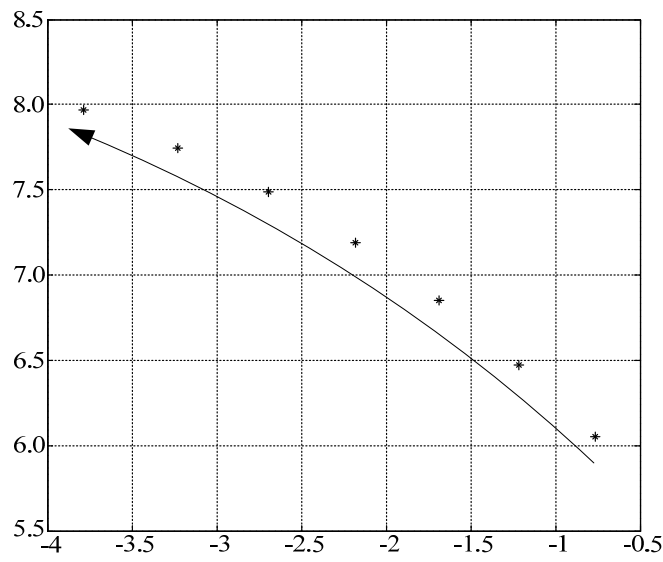

Figure 8. The eigenvalue locus under varying Ki.

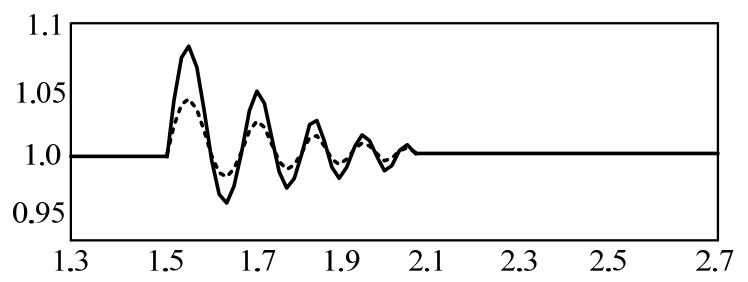

Figure 9. The time domain simulation result.

\section{Conclusions}

A lineared mathematical model for small signal stability analysis of VSC-HVDC transmission system collected with a DFIG based wind farm has been presented in this paper. The lineared model is based the state-space models. The state matrix is employed to investigate the small signal stability performance of the studied system through the eigenvalue analysis. The eigenvalue locus under different HVDC system control parameters is observed. It was validated that using the small-signal stability model, it was possible to design improved controllers for the VSCs of the multi-terminal dc network, which ensure stable network operation and enhanced dynamic 
performance. The time domain simulation also validated the analysis results.

\section{REFERENCES}

[1] R. Pena, J. C. Clare and G. M. Asher, "Double Fed Induction Generator using Back-to-back PWMconverter and its Application to Variable Speed Wind Energy Generation," Proceedings Institution Electric Engineering, Electric Power Applications, Vol. 143, No. 3, 1996, pp. 231-241. doi:10.1049/ip-epa:19960288

[2] T. Ackermann, "Transmission Systems for Offshore Wind Farms," IEEE Power Engineering Review, Vol. 22, No. 12, 2002, pp. 23-27. doi:10.1109/MPER.2002.1098040

[3] W. Lu and B. T. Ooi, "Optimal Acquisition and Aggregation of Offshore Wind Power by Multiterminal Voltage-source HVDC,” IEEE Transactions Power Delivery, Vol. 18, No. 1, 2003, pp. 201-206. doi:10.1109/TPWRD.2002.803826

[4] K. H. Sobrink, P. L. Sorensen, P. Christensen, N. Sandersen, K. Eriksson, and P. Holmberg, "DC Feeder for Connection of a Wind Farm," In Proceedings Cigre Symp., Malaysia, 1999.

[5] X. I. Koutiva, T. D. Vrionis, N. A. Vovos, and G. B. Giannakopoulos, "Optimal Integration of an Offshore Wind Farm to a Weak Grid,” IEEE Transactions Power Delivery, Vol. 21, No. 2, 2006, pp. 987-994. doi:10.1109/TPWRD.2005.859275

[6] D. Xiang, L. Ran, J. R. Bumby, P. Tavner, and S. Yang, "Coordinated Control of an HVDC Link and Doubly Fed Induction Generators in a Large Offshore Wind Farm," IEEE Transactions Power Delivery, Vol. 21, No. 1, 2006, pp.463-471.doi:10.1109/TPWRD.2005.858785

[7] L. Xu, L. Z. Yao, Christian Sasse. "Grid Integration of Large DFIG-based Wind Farms using VSC Transmission,” IEEE Transactions Power System, Vol. 22, No. 3, pp 2007, 976-984. doi:10.1109/TPWRS.2007.901306
[8] J. G. Slootweg, "Wind Power Modelling and Impact on Power Systems Dynamics,” Ph.D. Dissertation, Delft Univ. Technology, Delft, The Netherlands, 2003.

[9] V. Akhmatov, "Analysis of Dynamic Behaviour of Electric Power Systems with Large Amount of Wind Power," Ph.D. dissertation, Technology University Denmark, Lyngby, Denmark, 2003.

[10] D. Alvira, J. Arevalo, C. Bermudez, R. Granadino, A. Granda, C. Pincella, G.P. Stigliano, and R. Vailati, "Feasibility Studies of the HVDC Submarine Interconnection between the Spanish Peninsula and the Balearic Island of Mallorca," Presented at the 41th CIGREGen. Session, Paris, France, 2006, Paper B4-104. doi:10.1109/TEC.2004.832078

[11] M. V. A. Nunes, J. A. P. Lopes, H. H. Zurn, U. H. Bezerra, and R. G. Almeida, "Influence of the Variable-speed wind Generators in Transient Stability Margin of the Conventional Generators Integrated in Electrical Grids," IEEE Transctions Energy Conversion, Vol. 19, No. 4, 2004, pp. 692-701. doi:10.1109/TPWRS.2005.857275

[12] F. M. Hughes, O. Anaya-Lara, N. Jenkins, and G. Strbac, "Control of DFIG-based Wind Generation for Power Network Support,” IEEE Transactions Power System, Vol. 20, No. 4, 2005, pp. 1958-1966.

[13] R. S. Pena, "Vector Control Strategies for a Doubly-fed induction Generator Driven by a Wind Turbine,” Ph.D. Dissertation, University Nottingham, Nottingham, U.K., 1996.

[14] F. Mei and B. Pal, "Modal Analysis of Grid-connected doubly-fed Induction Generators," IEEE Transactions Energy Conversions, Vol. 22, No. 3, 2007, pp. 728-736. doi:10.1109/TEC.2006.881080

[15] G. O. Kalcon, G. P. Adam, Olimpo Anaya-Lara, Stephen Lo, and Kjetil Uhlen. "Small-Signal Stability Analysis of Multi-Terminal VSC-Based DC Transmission Systems," IEEE Transactions Power System, Vol. 27, No. 4, 2012, pp.1818-1830. doi:10.1109/TPWRS.2012.2190531 